\title{
Study on the Effect of Spiritual Leadership on Employees' Proactive Behavior
}

\author{
Li Kaiqin, Deng Zhihua*
}

School of Business Administration, Guizhou University of Finance and Economics, Guiyang, Guizhou

Keywords: Spiritual leadership; Proactive behavior; Spiritual capital; Mediating effect

\begin{abstract}
The proproactive behavior of employees is of great significance to the sustainable development of the organization and the healthy growth of employees. By analyzing the direct influence of spiritual leadership on the proactive behavior of employees and the indirect influence exerted by spiritual capital before and after the mediating variables are included, this paper uses SPSS18.0 and LISREL8.70 software to carry out statistical analysis on 243 sets of effective questionnaire data of supervisor employee pairing. The results show that spiritual leadership has a positive impact on employees' spiritual capital and active behavior. After the mediating variables are included, the part of employee's spiritual capital mediates the positive influence of spiritual leadership on employee's active behavior. This is of great significance to enhance the effectiveness of spiritual leadership behavior and stimulate the initiative of employees.
\end{abstract}

\section{Introduction}

The importance of proactive behavior to organizational development and employee growth is self-evident: leaders should be active and enterprising; managers should actively carry out team building, actively and effectively coordinate and communicate when encountering conflicts, actively understand and care about employees' working conditions, mobilize employees' enthusiasm and enthusiasm for work, and let employees maintain a positive and optimistic working attitude; New employees should actively integrate into the team and actively adapt to the environment; for the organization, the employees with high value are also those with positive attitude, active work, positive advice and active communication with the management.

So, what are the sources of employee vitality and positivity? Transpersonal psychology clearly points out that spirit is always the core essence of an individual, and it is spirit that provides support for self. Only through the order and structure of spirit psychology behavior can we truly understand an individual [1].

In terms of the leadership factors that stimulate employees' initiative behavior, the previous leadership theories have not paid enough attention to the fundamental existence of individuals spirituality, most of which focus on the rational and behavioral level of organizational members. As a new interdisciplinary research field of positive psychology, spirituality and leadership, the positive role of spiritual leadership in management practice has been widely concerned by the society, including the values, attitudes and behaviors necessary to meet employees' spiritual needs and mental health, which can cultivate employees' positive psychological quality, enhance employees' spiritual strength, and To stimulate the enthusiasm of employees fundamentally has obvious effect on solving the spiritual problems of the whole country, such as the negative, pessimistic, decadent, etc. it is urgent for the country, enterprises and society to study the spiritual leadership, which has a strong timeliness and pertinence. Therefore, it is highly concerned by the academic community, and it is a brand-new and valuable topic at home and abroad.

This study focuses on the following two questions: (1) what is the effect of spiritual leadership on employees' initiative in China? Therefore, it is necessary to carry out extensive field research and empirical research; (2) what is the internal mechanism of the influence of spiritual leadership on employees' active behavior? How is this "black box" process realized? Therefore, it is necessary to study the role and process mechanism of spiritual leadership. 


\section{Literature Review and Research Hypothesis}

\subsection{Spiritual leadership and spiritual capital}

Fry [2] defines the connotation of spiritual leadership, which is widely used in academic circles. Spiritual leadership refers to the leadership style that inspires oneself and others to have spiritual values, attitudes and behaviors based on the sense of mission and identity. According to fry [2], spiritual leadership includes three dimensions: vision, hope or belief, altruistic love.

Emmons [3] first proposed the concept of spiritual capital, defined it as "the ability to use spiritual resources adaptively to solve daily problems and achieve goals", and pointed out five components of spiritual capital: transcending the material world, experiencing high-dimensional consciousness, advocating high-level daily experience, solving problems with spiritual resources, integrity and goodness. Zohar \&amp; Marshall [4] defined spiritual capital as "human's unique spiritual qualification to deal with the meaning and value of life", and pointed out that spiritual capital has the following characteristics: spontaneity, self-awareness, value and meaning orientation, overall view, empathy, tolerance of differences, firm stand, humility, root seeking, construction ability, calm in the face of setbacks and sense of mission.

Spiritual leadership can meet the spiritual needs of employees based on their sense of mission and membership, cultivate their sense of mission, guide them to find the significance of their work, help them establish firm spiritual beliefs and actively face adversity, influence them internally through common vision and beliefs, guide them to carry forward the spirit of sincerity and trust, and enhance their ability to deal with setbacks Power. Some studies have shown that the individual's spiritual capital is influenced by the leadership style of the boss. For example, the leadership style that advocates morale and values productivity has a significant impact on the spiritual capital of subordinates [5], and the transformational leadership style of superiors also has a significant positive correlation with the spiritual capital of subordinates [6]. Therefore, it is proposed that:

Hypothesis 1 (H1): spiritual leadership positively affects employees' spiritual capital

\subsection{Spiritual leadership and proactive behavior}

Proproactive behavior refers to a kind of behavior mode that employees look to the future and actively seek change to improve performance [7], that is, self guided and future focused employee behavior in the organization [8], which brings positive changes, including changing themselves and the environment. Vakulov [9] thinks that individual innovation behavior is an important manifestation of active behavior. Ashford \&amp; Black [10] thinks that proactive behavior mainly includes information search behavior, positive cognitive behavior, relationship building behavior, work negotiation behavior and feedback search behavior. Dyne \&amp; Lepine [11] believed that voice behavior was an important manifestation of active behavior, while Frese \&amp; Fay [12] believed that proactive behavior was an individual's professional initiative, while Parker et al [13] believed that proactive behavior was an active implementation behavior, an active response to problems and an active service behavior. It can be seen from the meaning and performance of proactive behavior that proactive behavior requires employees to hold a positive attitude, think more flexibly, dig out their psychological potential, positive emotions and positive forces, so as to improve their work advantages and organizational performance.

However, employees' active behaviors are not always supported and recognized by the organization and others. Even in the environment of "money is the first bird", it is difficult for employees to deal with the ridicule and frustration from the organizational environment alone. At this time, the firm belief displayed by spiritual leaders has the role of model demonstration and inspiration for employees' active behaviors, motivating employees' enterprising spirit and serving employees actively, positively, efficiently and actively put into work to provide guarantee, so that employees' initiative behavior can be persisted in the face of risks or difficulties. Empirical research shows that spiritual leadership has a positive impact on organizational commitment, productivity and team military performance [14], and has a positive impact on organizational citizenship behavior, such as altruistic behavior, dedication to duty, athlete spirit, politeness, civic virtue [15]. Therefore, the following assumptions are proposed: 
Hypothesis 2 (H2): Spiritual leadership positively affects employees' initiative

\subsection{The mediating role of spiritual capital}

According to the previous theoretical analysis and literature research, due to the unique effect of spiritual leadership in the aspects of spiritual factors, its path of action is mainly through the influence of employees' mental state and then affect employees' external behavior. According to Emmons (2000) and Zohar \&amp; Marshall (2000), we can see that high-level spiritual capital enables employees to have strong spiritual strength, not depressed when their active behaviors are faced with challenges, risks and uncertainties, to think about problems from the perspective of integrity and justification, to reflect on themselves and the environment humbly, and to pay attention to external information New cognition, interpretation and construction, use of spiritual resources and special consciousness to explore the purpose and significance again; keep initiative in career and life, maintain a good working relationship, actively implement the tasks assigned by the organization and superiors, properly advise leaders and colleagues, and actively serve customers. Such employees are scarce resources of the organization, and their personal careers will be greatly different Color. Research shows that spiritual capital plays a supporting role in emotional intelligence [4], and also affects the professional purpose and sense of work significance. It also stimulates employees' self-development, harmonious coexistence, self-expression, service to others and other behaviors [16]; it enables members to achieve a sustained and healthy psychological state, and the enterprise is full of vitality and inspiring morale [17]. Therefore, the following assumptions are proposed:

Hypothesis 3 (H3): spiritual capital plays an mediating role between spiritual leadership and employees' active behavior.

\section{Research Design}

\subsection{Procedures and samples}

In order to overcome the problem of common method variance (CMV) and improve the reliability and validity of the study, the data were collected by supervisor employee matching survey. First, the supervisor questionnaire is compiled to let the supervisor report the variables such as employee's spiritual capital and active behavior. Then, a questionnaire was developed to let employees report perceived leader's mental leadership behavior, and the questionnaire of employees was matched with the questionnaire of leader evaluation. 296 sets of supervisor employee matching questionnaires were distributed on the site of enterprise management training. The filling method is: if you are an ordinary employee, fill in the employee questionnaire; if you are a manager and have subordinates, fill in the supervisor questionnaire and take it back on the spot, then take the corresponding supervisor questionnaire or employee questionnaire back to your supervisor or subordinates for filling, and then hand it over to the human resources department of the company. After eliminating the waste papers that are not seriously answered (such as obvious and regular check), 243 sets of effective questionnaires are obtained, and the total recovery rate of the questionnaire is $82.09 \%$. A total of 452 employees and supervisors from 32 enterprises participated in the questionnaire survey, including 9 state-owned holding enterprises, 16 private enterprises, 3 Foreign-funded enterprises and 4 Sino foreign joint ventures. The sample overview is shown in Table 1.

Table 1 Samples overview unit: \%.

\begin{tabular}{|c|c|c|c|c|c|c|c|c|c|}
\hline \multirow{2}{*}{} & \multicolumn{2}{|c|}{ Gender } & \multicolumn{3}{c|}{ Education level } & & \multicolumn{2}{c|}{ Age } \\
\cline { 2 - 11 } & male & femal & $\begin{array}{c}\text { Below } \\
\text { University }\end{array}$ & University & $\begin{array}{c}\text { Graduate } \\
\text { student }\end{array}$ & $\begin{array}{c}\text { Under } \\
30 \text { years } \\
\text { old }\end{array}$ & $\begin{array}{c}\text { between30 } \\
\text { to 45 years } \\
\text { old }\end{array}$ & $\begin{array}{c}\text { Over 45 } \\
\text { years old }\end{array}$ \\
\hline $\begin{array}{c}\text { Executive } \\
\text { director }\end{array}$ & Proportion & 65.44 & 34.56 & 18.54 & 66.44 & 15.02 & 10.24 & 52.24 & 37.52 \\
\hline Staff & Proportion & 55.62 & 44.38 & 13.20 & 66.35 & 20.45 & 44.32 & 42.24 & 13.44 \\
\hline
\end{tabular}




\subsection{Variable measurement}

The mental leadership adopts the scale developed by Fry [18], which includes three dimensions: vision, hope or belief, altruistic love, specifically including 17 items such as "my boss shows a strong sense of mission in work". Spiritual capital adopts the single dimension questionnaire developed by Yazdi [19], specifically including 12 items such as "my subordinates will actively face their own adversity". The scale developed by Rita et al [20] was used for active behavior, specifically including six items such as "my subordinates are good at discovering opportunities". The questionnaire uses Likert scale to score 5 points, 5 points for "full agreement", 4 points for "comparative agreement", 3 points for "neutral", 2 points for "comparative disagreement", and 1 point for "total disagreement". The common demographic characteristics such as gender, age (age), education level and so on are the control variables.

\section{Data Analysis}

\subsection{Reliability and validity analysis}

Use SPSS18.0 statistical analysis software to analyze the reliability of each variable. Cronbach's $\alpha$ coefficient was used to test the reliability of each variable. The corresponding Cronbach's $\alpha$ value is shown in the diagonal of Table 2. The Cronbach's $\alpha$ coefficient of the four subscales is higher than 0.7, indicating that the data has a high reliability and meets the requirements of statistical test. LISREL8.70 statistical analysis software was used to analyze the validity of each variable, confirmatory factor analysis (CFA) was used to analyze each variable, $\chi^{2} / \mathrm{D} f$, AGFI, RMSEA, NNFI, CFI, SRMR and other fitting indicators and their corresponding critical values were used to judge, and the indicators and values of each variable are shown in Table 2.

Table 2 Confirmatory factor analysis indexes and values of each scale.

\begin{tabular}{|c|c|c|c|c|c|c|}
\hline & $\chi^{2 / \mathrm{d} f}$ & AGFI & RMSEA & NNFI & CFI & SRMR \\
\hline $\begin{array}{c}\text { Spiritual } \\
\text { leadership }\end{array}$ & 3.245 & 0.941 & 0.084 & 0.915 & 0.952 & 0.040 \\
\hline Spiritual capital & 3.012 & 0.941 & 0.081 & 0.974 & 0.973 & 0.044 \\
\hline Proactive behavior & 3.565 & 0.912 & 0.077 & 0.915 & 0.924 & 0.047 \\
\hline
\end{tabular}

According to table 2, the index values of AGFI, nnfi and CFI of each variable exceed the requirements of 0.9, the RMSEA value of the variable is less than 0.1, and the SRMR value of the variable is also less than 0.05 , indicating that the validity index value of each variable reaches the required critical value, indicating that the fitting condition is good and the data quality requirements can be met.

\subsection{Correlation analysis}

Use SPSS18.0 statistical analysis software to calculate the mean value, standard deviation and correlation coefficient between variables. Pearson correlation coefficient is used as the correlation coefficient. See Table 3 for specific values.

Table 3 Standard deviation and correlation coefficient of variables.

\begin{tabular}{|c|c|c|c|c|c|}
\hline Variable name & Mean & S.D. & 1 & 2 & 3 \\
\hline Spiritual leadership & 3.5214 & .84516 & $(.815)$ & & \\
\hline Spiritual capital & 3.5487 & .82309 & $.512^{* *}$ & $(.795)$ & \\
\hline Proactive behavior & 3.8451 & .76854 & $.514^{* *}$ & $.463^{*}$ & $(.857)$ \\
\hline
\end{tabular}

It can be seen from table 3 that mental leadership is positively correlated with mental capital and active behavior, with correlation coefficients of 0.512 ( $\mathrm{p}<0.01), 0.476(\mathrm{p}<0.01)$ and 0.514 ( $\mathrm{p}<$ 0.01 ), respectively, and mental capital is positively correlated with active behavior, with correlation coefficients of $0.463(\mathrm{p}<0.05)$ and $0.532(\mathrm{p}<0.05)$, which lays a foundation for hypothesis testing.

\subsection{Direct effect test}

First of all, test the direct effect of independent variable spiritual leadership, use SEM theory to build the model, use LISREL8.70 statistical software for data analysis, the model and corresponding 
effect are shown in Figure 1.

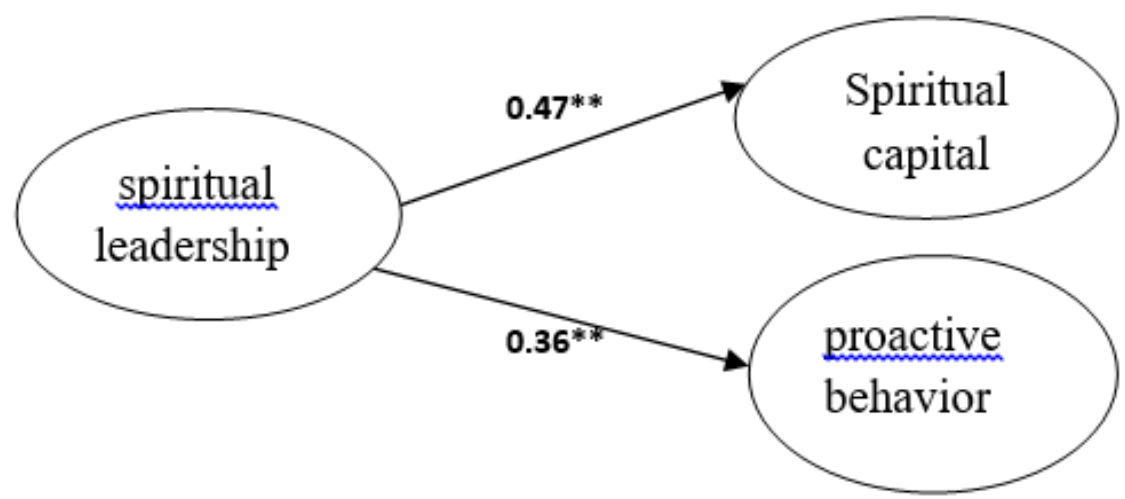

Figure 1 The direct effect of spiritual leadership.

The results showed that mental leadership significantly positively affected mental capital $(\beta=$ $0.47, \mathrm{p}<0.01)$, hypothesis 1 was verified, significant positively affected proactive behavior $(\beta=$ $0.36, \mathrm{P}<0.01$ ), and hypothesis 3 was verified.

\subsection{Mediating effect test}

The four step method proposed by Baron and Kenny [21] was used to test the mediating effect. It can be seen from table 3 that: (1) there is a significant positive correlation between independent variable mental leadership and outcome variable active behavior, with a correlation coefficient of 0.514 ( $\mathrm{p}<0.01)$, (2) there is a significant positive correlation between independent variable mental leadership and mediating variable mental capital, with a correlation coefficient of $0.512(\mathrm{p}<0.01)$, (3) there is a significant positive correlation between mediating variable mental capital and outcome variable active behavior, with a correlation coefficient of $0.463(\mathrm{p}<0.05)$, (4) after the mediating variable mental capital is incorporated into the structural equation model (as shown in Figure 2), the influence of mental leadership on proactive behavior is reduced from $\beta=0.36(\mathrm{P}<0.01)$ to $\beta=0.28$ $(\mathrm{P}<0.01)$, which indicates that mental capital partially mediates the positive influence of mental leadership on active behavior.

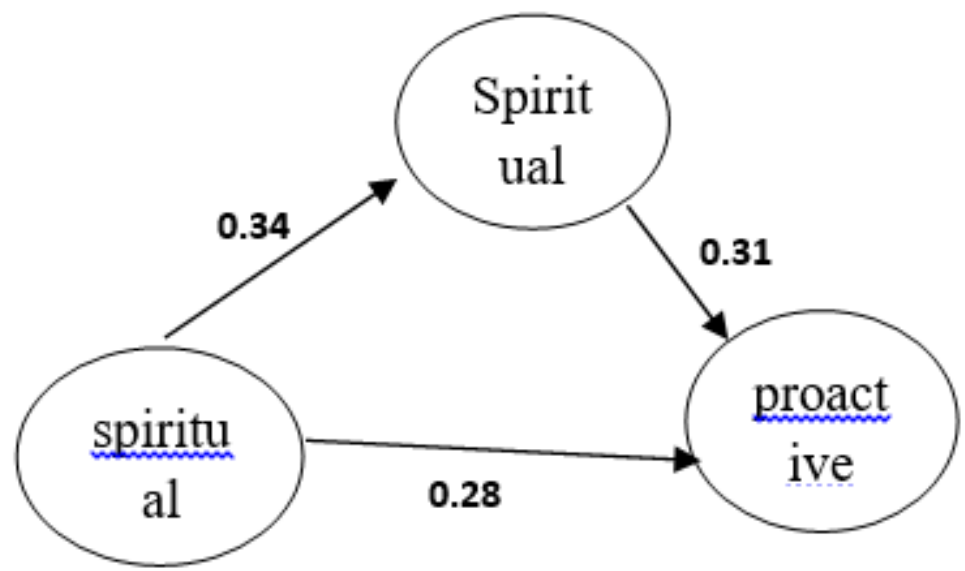

Figure 2 Mediating role of spiritual capital.

\section{Conclusion and Prospect}

\subsection{Conclusion and significance}

This paper analyzes the direct influence of spiritual leadership on employee's active behavior, the effect and internal mechanism of indirect influence on employee's proactive behavior through spiritual capital, and conducts empirical test based on 243 pairs of supervisor employee 
questionnaires. The results show that spiritual leadership has a positive impact on employees' spiritual capital and active behavior. After the mediating variables are included, the part of employee's spiritual capital mediates the positive influence of spiritual leadership on employee's active behavior.

Through the integration of the frontier research of spirituality, leadership and active organizational behavior, this paper constructs a theoretical model of the influence of spiritual leadership on employees' active behavior, and conducts empirical tests to explore and verify the mechanism and internal law of the influence of spiritual leadership on employees' proactive behavior through spiritual and psychological factors. This is a beneficial attempt of empirical research on the effect and mechanism of mental leadership in domestic academic circles. It will gain new leadership advantages for stimulating employees' proactive behavior and provide important enlightenment for improving the leadership effectiveness of mental leadership in China. Spiritual leadership can exert significant influence on employees' active behavior, which opens up a new perspective for managers to improve employees' active behavior. On the basis of the traditional material benefits incentive, the leaders of enterprises take the vision incentive to employees, pay attention to the cultivation of employees' hopes and beliefs, care for and meet the needs of employees' spiritual existence, show selfless care for employees, strengthen employees' sense of mission and membership and other spiritual leadership methods, which can stimulate employees' active behavior.

\subsection{Limitations and prospects}

Although a relatively mature scale developed by foreign scholars is adopted, in order to adapt to China's economic, social and cultural background, exploratory and open local research should be carried out in China, so as to clarify the local characteristics and structural dimensions of key variables such as spiritual leadership, and develop corresponding measurement tools. In addition, the future research can adopt the tracking research design to break through the relatively static research ideas, match the data collected at different time points, obtain the available longitudinal matching data continuously in time, and carry out statistical analysis and tracking research, which can more objectively and effectively explore the causal relationship between variables.

\section{References}

[1] Guo Yongyu, the formation and development of suprapersonal psychology, foreign social sciences, 2001 (3): 39-42

[2] Fry L. W. Toward a Theory of Spiritual Leadership. Leadership Quarterly, 2003, 14(6): 693-727.

[3] Emmons R. A. Is Spirituality an Intelligence? Motivation, Cognition, and the Psychology of Ultimate Concern. International Journal for the Psychology of Religion, 2000, 10(1): 3-26.

[4] Zohar D., Marshall I. Spiritual Intelligence, the Ultimate Intelligence?. Bloomsbury, London, 2000.

[5] Bagherpour M., Abdollahzadeh H. Relationship between Spiritual Intelligence and Leadership Style of Managers of Secondary Schools in the City of Gorgan. Quarterly Journal of New Approach in Educational Administration, 2012, 3(2): 87-98.

[6] Aliakbar A., Hadiseh R. Studing of Relationship between Transformational Leadership Style with Emotional Intelligence and Spiritual Intelligence. International Journal of Research in Management, 2013, 4 (3): 56-65.

[7] Bindl U. K, Parker S. K. Proactive Work Behavior: Forward-thinking and Change-oriented Action in Organizations. // Zedeck, Sheldon (Ed), (2011). APA Handbook of Industrial and Organizational Psychology. American Psychological Association, 2011: 567-598.

[8] Parker S. K., Collins C. G. Taking Stock: Integrating and Differentiating Multiple Proactive 
Behaviors. Journal of Management, 2010, 36(3): 633-662.

[9] Vakulov B. G., Samko S. G., Bruce R. A. Determinants of Innovative Behavior: A Path Model of Individual Innovation in the Workplace. Academy of Management Journal, 1994, 37(3): 580-607.

[10] Ashford S. J., Black J. S. Proactivity during Organizational Entry: The Role of Desire for Control. Journal of Applied Psychology, 1996, 81 (2): 199-214.

[11] Dyne L. V., Lepine J. A. Helping and Voice Extra-role Behaviors: Evidence of Construct and Predictive Validity. Academy of Management Journal, 1998, 41(1): 108-119.

[12] Frese M., Fay D. Personal Initiative: An Active Performance Concept for Work in the 21st Century. Research in Organizational Behavior, 2001, 23(2): 133-187.

[13] Parker S. K., Williams H. M., Nick T. Modeling the Antecedents of Proproactive behaviorat Work. Journal of Applied Psychology, 2006, 91(3): 636-52.

[14] Fry L. W., Hannah S. T., Noel M., Walumbwa F. O. Impact of Spiritual Leadership on Unit Performance. Leadership Quarterly, 2011, 22(2): 259- 270.

[15] Kaya A. The Relationship between Spiritual Leadership and Organizational Citizenship Behaviors: A Research on School Principals' Behaviors. Educational Sciences Theory \&amp; Practice, 2015, 15:597-606.

[16] Lipswiersma M. The Influence of Spiritual 'Meaning-making' on Career Behavior. Journal of Management Development, 2002, 21(7): 497-520.

[17] Moxley R. S. Leadership and Spirit [M].San Francisco, CA: Jossey Bass, 2000.

[18] Fry L. W., Vitucci S., Cedillo M. Spiritual Leadership and Army Transformation: Theory, Measurement, and Establishing a Baseline. Leadership Quarterly, 2005, 16(5): 835-862.

[19] Yazdi M. R. Quantitative Assessment of Spiritual Capital in Changing Organizations by Principal Component Analysis and Fuzzy Clustering. Journal of Organizational Change Management, 2015, 28(3).

[20] Rita C., Colin B., Björn L. Unidimensionality of Abbreviated Proactive Personality Scales across Cultures. Applied Psychology, 2005, 54(4): 476-489.

[21] Preacher K. J., Hayes A. F. Asymptotic and Resampling Strategies for Assessing and Comparing Indirect Effects in Multiple Mediator Models. Behavior Research Methods, 2008, 40(3): 879-891. 